\title{
INVESTIGATION ON FLEXURAL BEHAVIORS OF I-SHAPED JOINTED COMPOSITE PLATES
}

\author{
Gurkan Altan ${ }^{1}$ \\ Department of Mechanical Engineering, Faculty of Engineering, Pamukkale University, Kinikli 20070 Denizli, \\ Turkey, e-mail: gurkanaltan@pau.edu.tr
}

Received: 2017.12.21

Accepted: 2018.04.04

Published: 2018.06.01

\begin{abstract}
In this study, the flexural behaviors of a composite plate jointed with I profile jointing element have been carried out experimentally and numerically. As a load type, four point flexural tests have been used in order to study performances of jointed composite plates under bending load. The effects of jointing geometry parameters ratio of the width of lock to width of semi-specimen $(\mathrm{b} / \mathrm{W})$, lock middle/end width to the width of lock $(\mathrm{z} / \mathrm{b})$ and the length of lock to the width of semi-specimen $(\mathrm{h} / 2 \mathrm{~W})$ have been investigated. According to the investigation optimum jointing parameters have been found with the $\mathrm{h} / 2 \mathrm{w}$ ratio of $0.5, \mathrm{~b} / \mathrm{w}$ ratio of 0.5 and $\mathrm{z} / \mathrm{b}$ ratio of 0.5 . Abaqus 6.11 finite element program has been used in order to support the results obtained from the experiments. Damages have been mostly seen on jointing lock elements.
\end{abstract}

Keywords: Four point bending, Geometric joint, Failure behaviour, Butt, Composite.

\section{INTRODUCTION}

Structures composed of composite materials are generally used under static and dynamic loading conditions. Due to production and designing conditions, some composite structures may be formed with one or more joint. The main objective here is to transfer force from the main structure through jointing two or more materials. The most important problem in composite materials is the damage happening in joint points. Joints may be studied in two main classes as mechanic and bonding joints. Bonding joint is a jointing technique that can be used in place of conventional methods like mechanic jointing. Joints made with adhesive are single lap joint, double lap joint, beveled lap joint, angeled lap joint, butt joint, stepped joint, single reinforced butt joint, double reinforced butt joint and cylindrical lap joint [1].

The most frequently used system in composite materials as a mechanical jointing type is bolted joint. There are advantages and disadvantages between joint with bonding and mechanic joint. The technique for joint with adhesive may offer more than one benefits, such as jointing materials of a variety of characteristics, removing irregularities that may arise through joint elements such as bolt and rivet. Besides, bonding provides more steady stress distribution along the entire surface. It also provides savings in terms of weight and costs and thin materials may be jointed in a more strength way. Bolted joint has various advantages than bonding joint. It enables demounting of the structure. Any element composing the structure may be changed easily. It is very difficult to change elements in structures jointed together through bonding method.

There is a variety of joint types available in the literature related to joint of composite materials. While some of these studies are about how joints are made, some of them are about static and dynamic performances of jointed systems. Pan et al. [2] investigated the influence of surface modification with carbon fiber on the flexural mechanical properties of bio-composites. Harman and Wang [3] optimized the profile of the scarf joint 
between dissimilar modulus adherents with an analytical method. Chen [4] examined the effects of hygrothermal cycling upon the performance of a bolted composite joint. He determined that the bolt torque relaxed as the number of environmental cycles increased. Avila and Bueno [5] carried out a performance study on a new design of a single-lap bonded joint, so called wavy-lap joint for laminate composites. Bahei-El-Din and Dvorak [6] examined, by finite-element computations, strength of new joint designs for adhesive bonding of tick multi-layered composite adherends. Grassi et al. [7] presented a simple and efficient computational approach for analysing the benefits of through thickness pins for restricting deboned failure in joints. Aktas et al. [8] carried out an experimental and numerical study to investigate the strength of a pinned-joint carbon epoxy composite plate. Megueni et al. [9] carried out a finite element method to analyze the evolution of the stress intensity factor for cracks repaired with bonded hygrothermal aged composite patches. Choi [10] investigated a failure area method to predict failure loads of mechanically-fastened composite joints under plane stress condition. Altan et al. [11] designed an experimentally and numerically study to analyse the load-carrying capacities of composite structures connected face-to-face by a butterfly coupling component without adhesive. They also supported the results of the experimental studies with numerical analysis. Kumar et al. [12] carried out analytical and experimental analyses of composite epoxy adhesive joints. They also made comparison between the experimental and theoretical stresses. Kim et al. [13] carried out an experimental study on the effect of overlap length on the failure of composite-toaluminum single-lap bonded joints. They tested carbon composite-to-aluminum single-lap adhesive joints with six different bonding lengths under tension. Seo et al. [14] used the epoxy-based adhesive metal butt joints to evaluate the strength and failure probability. They conducted the conventional test methods such as tensile, shear and four-point bending tests to evaluate the probability distribution of adhesive strength. Nader et al. [15] investigated the size effects associated with length and width, on the bending strength of marine grade polymer matrix laminated composites. They developed a new expression for predicting the strength size effect. Dawood et al. [16] conducted to evaluate the two-way bending behavior of 3-D glass fiber reinforced polymer sandwich panels. Khalili et al. [17] studied experimentally the effect of reinforcements in the adhesive layer using a single lap joint with composite adherends. Ding et al. [18] carried out an analysis of bondedbolted steel butt joints with particular attention to the effect of the loss of bolt tightness to the structural behavior. Abad et al. [19] carried out an analysis of a bolted lap joint, subjected to a relative displacement after applying a pre-stress on the bolt in order to characterize the joint behavior. Aydin and Temiz [20] analyzed the mechanical behavior of double lap joints bonded.

In this study, joint performance by changing joint geometry of mechanic butt joints made with I profile joint element that can be used instead of butt joints bonded on composite structures has been analyzed. The results of experimental studies are supported with numerical analysis.

\section{DETERMINATION OF MECHANICAL PROPERTIES OF COMPOSITE MATERIALS}

In accordance with ASTM standards, test specimens have been sized and properties have been determined under static tensile strength, compression strength and shear strength. According to ASTM 3039-76 standard, longitudinal elasticity modulus $\left(\mathrm{E}_{1}\right)$, Poisson ratio $\left(v_{12}\right)$ and longitudinal tensile strength $\left(\mathrm{X}_{t}\right)$ have been determined from specimens. Transverse elasticity modulus $\left(\mathrm{E}_{2}\right)$ and transverse tensile strength $\left(\mathrm{Y}_{\mathrm{t}}\right)$ have been determined according to ASTM 303976 standard from test specimens. According to ASTM 3410-75 standard test method, longitudinal compressive strength $\left(\mathrm{X}_{c}\right)$ has been measured from the test specimens through unidirectional static compression method. According to ASTM 3518-76 standard test method, shear modulus property $\left(G_{12}\right)$ has been determined. Shear modulus has been calculated by measuring the strains along with tensile direction. Due to the strain of shear specimen in the direction of tensile loading, elasticity modulus has been calculated according to Jones [21].

$$
G_{12}=\frac{1}{\frac{4}{E_{x}}-\frac{1}{E_{1}}-\frac{1}{E_{2}}+\frac{2 v_{12}}{E_{1}}}(M P a)
$$

According to ASTM D 5379 standard test method, Iosipescu shear strength method has been used to determine the shear strength (S). This mechanical property has been obtained from Iosipescu shear test apparatus based on the speci- 
men. A pure shear load has been created where there is no flexure between notches of the specimen through Iosipescu loading apparatus. Maximum shear load occurred in loading apparatus has been used and shear yield strength has been calculated by using the following equation [22].

$$
S=\frac{F_{\max }}{t . c}(M P a)
$$

Mechanical properties of composite materials obtained from experiments at room temperatures are given in Table 1.

\section{ANALYSIS PROCEDURE}

Optimization of jointing element has been carried out through four points flexural loading both experimentally and numerically. In this study, composite plates have been used as glass fiber sequence $[0 / 90]_{2 \mathrm{~s}}$. Composite plates have been jointed with mechanical butt joint. I profile jointing elements have been used for butt joints of composite plates through close-fit method. Tolerance for the close-fit method has been taken as $3 \%$. Specimens have been cut from this mechanical butt jointed composite plate. Sequence layer and material of I profile jointing elements has taken same with the sequence layer and material of semi-specimens. The effects of jointing geometry parameters ratio of the width of lock to width of semi-specimen (b/W), lock middle/end width to the width of lock $(\mathrm{z} / \mathrm{b})$ and the length of lock to the width of semi-specimen $(\mathrm{h} / 2 \mathrm{~W})$ have been investigated (Figure 1).

In Table 2, the dimensions defining the geometry of I profile jointing element are given. Optimization has been realized in all ratios possible for production.

Four points bending tests has been made with Instron 8801 equipment with $50 \mathrm{kN}$ load capacity. All specimens have been loaded at $1 \mathrm{~mm} / \mathrm{min}$. constant jaw speed. For each model, jointing (damage) load-jointing displacement graphics have been drawn. When a slight decrease is observed in the load applied, experiment is ended. Damage load of the specimen happens at time of first gradient in the load applied. In order to understand types of damages, experiments with some specimen have been lasted until their last damages. By this way, the effects of jointing geometry have been studied.

In numerical analysis carried out through finite element method, Abaqus 6.11 program has been used. As shown in Figure 2, specimen jointed with lock jointing elements has been modelled in three dimensional modelling. Since geometries of jointing elements are changed, it is of great importance to know stress on lock jointing and determination of damage areas for the safety of the structure. Therefore, a more fine mesh than mesh on semi-specimen has been made for lock jointing element. Stress distribution on various jointing in different geometries, stresses of the lock jointing (Route 1 and Route 2) has been dealt with, as shown in Figure 2. In analysis, load value has been selected as $30 \mathrm{~N} / \mathrm{mm}^{3}$ in order to make a comparison. Stress values obtained from stress analysis conducted under the same load have been different due to different $\mathrm{z} / \mathrm{b}$ ratios.

\section{RESULTS AND DISCUSSIONS}

Load carrying capacities of the specimen made at various ratios such as $(\mathrm{h} / 2 \mathrm{~W})$ and $(\mathrm{b} / \mathrm{W})$ than $(\mathrm{z} / \mathrm{b})$ ratios are shown in Figure 3. As can be seen from the figures, load carrying capacity depends on $(\mathrm{z} / \mathrm{b}),(\mathrm{b} / \mathrm{W})$ and $(\mathrm{h} / 2 \mathrm{~W})$ ratios. When $(\mathrm{h} / 2 \mathrm{~W})$ ratio is 0.5 ; load carrying capacity of the locked specimen is higher than other lengths. From the figure, it can be seen that joint load values are the highest at $0.5(\mathrm{~h} / 2 \mathrm{~W})$ ratios and especially at $0.5(\mathrm{z} / \mathrm{b})$ ratios. If the joint load is 0.3 of $(\mathrm{h} / 2 \mathrm{~W})$ ratio, it has been found lower than that of various $(\mathrm{z} / \mathrm{b})$ values as cross sections decrease depending on geometry. When joint loads have been examined in terms of $(b / W)$ ratio, $(h / 2 W)$ ratio at 0.3 and 0.5 values and the ratio at 0.5 and 0.6 values have been obtained as maximum. When $(\mathrm{h} / 2 \mathrm{~W})$ ratio has been at 0.7 values, joint load has been found as maximum at 0.4 value of (b/W) ratio. Load transfer loss over the jointing as a result of amount of deflection increased due to extension of the length of jointing element may be a cause for this. According to the test results, maximum joint load has been obtained at 0.6 value of $(\mathrm{b} / \mathrm{W})$ ratio and 0.3 value of $(\mathrm{z} / \mathrm{b})$ ratio for 0.3 value of $(\mathrm{h} / 2 \mathrm{~W})$ ratio. Maximum joint load has been obtained at 0.5 value of $(b / W)$ ratio and 0.5 value of $(\mathrm{z} / \mathrm{b})$ ratio for 0.5 value of $(\mathrm{h} / 2 \mathrm{~W})$ ratio. For 0.7 value of $(\mathrm{h} / 2 \mathrm{~W})$, maximum joint load has been obtained at 0.4 value of $(\mathrm{b} / \mathrm{W})$ and 0.4 value of $(\mathrm{z} / \mathrm{b})$ value. As a result of this, it has been determined that choosing middle and end width of lock jointing is of great importance for load carrying capacity. Moreover, change in maximum damage loads through increase in 
(b/w) and $(\mathrm{h} / 2 \mathrm{~W})$ ratios shows the importance of width and length of lock jointing.

Changes in maximum Load carrying capacities of lock jointing and types of damages for different length of locks are shown in Figure 4. As can be seen from the figure, for 0.5 value of lock length $(\mathrm{h} / 2 \mathrm{~W})$ ratio jointing load capacity has been determined maximum at 0.5 value of $(b / W)$ ratio and 0.5 value of $(\mathrm{z} / \mathrm{b})$ ratio. Therefore, in this study, specimens of 0.5 value of lock length $(\mathrm{h} / 2 \mathrm{~W})$ ratio have been analyzed separately. Furthermore, for other length of locks, separate analysis has been carried out. In the figure, damage types resulting from change in $(\mathrm{h} / 2 \mathrm{~W})$ ratio at 0.5 value of $(\mathrm{b} / \mathrm{W})$ ratio and 0.5 value of $(\mathrm{z} / \mathrm{b})$ ratio are shown.

For 0.5 value of the jointing length ratio $(\mathrm{h} / 2 \mathrm{~W})$ of the jointed specimens formed with lock jointing elements made of composite plates, changes in load carrying capacity is shown in Figure 5. As the ratio of width of lock to the width of the specimen $(b / W)$ increases, jointing displacement in maximum load capacities of the lock jointing increases have been observed as well. While the ratio of lock width to specimen width $(b / W)$ is 0.5 , it has been found that specimen carries maximum flexural load at all value of $(\mathrm{z} / \mathrm{b})$ ratio comparing to other specimens. When load carrying capacities of the specimens having $0.3(\mathrm{z} / \mathrm{b})$ ratios have been compared to the others, $(\mathrm{b} / \mathrm{W})$ ratio increases up to 0.5 and stays approximately at the same value afterwards. Similarly, when load carrying capacities of the specimens having $0.5(\mathrm{z} / \mathrm{b})$ ratios have been compared to the others, $(\mathrm{b} / \mathrm{W})$ ratio increases up to 0.5 . According to the analysis, jointing load has been seen when $(\mathrm{b} / \mathrm{W})$ ratio is 0.5 and $(\mathrm{z} / \mathrm{b})$ ratio is 0.5 . Jointing displacement obtained from four points flexural load shows amount of deflection under such loads. Maximum deflection amount at different values of (b/W) ratio up to 0.4 and various $(\mathrm{z} / \mathrm{b})$ values is found as $2.3 \mathrm{~mm}$. However, in parallel with other increasing values of $(b / W)$ ratio; the amount of deflection has been increased. The amount of maximum deflection has been found as $3.2 \mathrm{~mm}$.

Due to four point flexural load, upper part of the lock has been exposed to compressive loading and lower part of the lock has been exposed to tensile loading. At smaller values of $(\mathrm{z} / \mathrm{b})$ ratio, shear damages have been found on bottom edge of the lock. At bigger values of $(\mathrm{z} / \mathrm{b})$ ratio, damages have occurred as matrix crushing together with the specimen.
Stress results obtained through the analysis using finite element methods have been obtained as numerical values. By establishing stress and normalized lock length graphics, highest stress values of the composite specimen during butt to butt joint and changes in stress could be analyzed. For the later stages of the analysis, it has been aimed to define most suitable specimen having highest load carrying capacity through analysis of stress distribution obtained and graphics formed.

Stress values of various $\mathrm{z} / \mathrm{b}$ ratios at $\mathrm{h} / 2 \mathrm{~W}=0.5$ and $b / W=0.5$ geometry parameters occurred along the Route 1 and Route 2 is shown in Figure 6 . It can be seen from the figure that jointings at $\mathrm{z} / \mathrm{b}=0.3$ and $\mathrm{z} / \mathrm{b}=0.4$ ratios are higher than those of Route 1 and Route 2. $z / b=0.4$ ratio of stress distribution of Route 1 and Route 2 in jointing at $\mathrm{z} / \mathrm{b}=0.3$ ratio is similar; however, low stress values have been obtained. Stress values occurred in jointings made at $\mathrm{z} / \mathrm{b}=0.5$ ratio is lower than those of obtained at other $\mathrm{z} / \mathrm{b}$ ratios. It has been expected that geometries by which lower stress values are obtained may achieve higher load carrying capacity. As a result, load carrying capacity in jointing at $z / b=0.5$ ratio will have higher damage load. As a result, load carrying capacity will be higher in jointing at $\mathrm{z} / \mathrm{b}=0.5$ ratio and therefore it will be damaged later.

Failure analysis of the specimen having the best load carrying capacity obtained through stress analyzing carried out with finite elements method has been made with the specimen having $\mathrm{h} / 2 \mathrm{~W}=0.5, \mathrm{~b} / \mathrm{W}=0.5, \mathrm{z} / \mathrm{b}=0.5$ ratios by applying Hashin failure Criteria. Accordingly, the results from stress analysis have been supported by the failure analysis. The zones where stress values are higher on composite structure have been found as the zones where damage occurs as a result of failure analysis. According to Hashin Failure Criteria, if failure index is one (1), damage occurs and damage loads are found through approximating failure index value to the value of 1 as a result of finite element analysis.

Since damage of semi-specimens jointed and modeled as laminated in Abaqus finite element program has been first formed on lock jointing, the first failure loads for both fiber and matrix of the composite plates composing lock jointing are given in Table 3. In this model, the volume of bending pin body where bending load has been applied is $27.5 \mathrm{~N} / \mathrm{mm}^{3}$. First obtained failure index is the failure index of the first damaged laminate in the composite. Considering composite 
laminate pile composed of eight plates, based on tests conducted, it can be said that any damage happening on one single plate may not affect the entire composite structure. Therefore, when cross sections have been examined, it is evident that the first matrix tensile failure occurs on the central plate and as the amount of loading increases, damage moves out of the surface of the specimen. As the second type of damage, matrix compression failure has been obtained and when damage index has been assessed, values have found very close to tensile failure index. Later, failure has been found on the compression of fiber and fiber tensile failures in higher amount of loadings.

When damage formation is analyzed along cross section, total damage or damages happen when they reach outer surface of the composite specimen. Accordingly, failure index occurred in maximum damage load of lock jointing is shown in Table 4. As can be seen from the table, failure index value of the matrix compression of the first damage on the outer surface of the composite structure is found as 1. As a result, maximum load values obtained from failure analysis and maximum load value obtained from the tests has supported each other.

\section{CONCLUSION}

In this study, the effects of different geometric parameters of I profile jointing element on damage loads of ( $\mathrm{z} / \mathrm{b}, \mathrm{b} / \mathrm{W}, \mathrm{h} / 2 \mathrm{~W})$ have been conducted both experimentally and through finite element analysis using ABAQUS package program. Experimental and numerical study has been conducted under four point flexural loading.

- Stress results for lock jointing element at different $\mathrm{h} / 2 \mathrm{~W}$ ratios are found. For each ratio, stress values have been analyzed and the most suitable parameter has been determined.

- The geometric ratios of I-jointing element have been found according to the maximum load carrying capacities.

- According to the tests, choosing lock end and medium width is of great importance in terms of load carrying capacity.

- During tests, at smaller values of $(\mathrm{z} / \mathrm{b})$ ratio, shear damages occur at bottom ends of the lock. As for bigger values of (z/b) ratio, damages first occur as matrix crush.

- The first damage load value obtained from the tests has been found very close to the load value obtained from Abaqus finite element program and the results overlap each other.
- It is not possible to repair main structure due to ruptures they may arise from sudden damage development in butt joint used. If butt joints are supported with I profile jointing element, damage formation is prevented and life cycle of the structure may be increased economically.

\section{ACKNOWLEDGEMENTS}

The authors would like to express their appreciation to the TUBITAK, Turkey, Project No: $110 \mathrm{M} 250$ for providing financial support for this study.

\section{REFERENCES}

1. Adams RD, Strength predictions for lap joints, especially with composite adherents. Journal of Adhesion 1989, 30, 219-242.

2. Pan Y, Chen Y, Shen Q, Pan C, Effect of carbon fiber surface modification on the flexural mechanical properties of carbon fiber reinforced polyetheretherketone biocomposites. Journal of Polymer Engineering 2015, 35/7, 657-663.

3. Harman $\mathrm{AB}$, Wang $\mathrm{CH}$, Improved design methods for scarf repairs to highly strained composite aircraft structure. Composite Structures 2008, 75, 132-144.

4. Chen HS, The static and fatigue strength of bolted joints in composites with hygrothermal cycling. Composite Structures 2001, 52, 295-306.

5. Avila FA, Bueno PO, An experimental and numerical study on adhesive joints for composites. Composite Structures 2004, 64, 531-537.

6. Bahei-El-Din YA, Dvorak GJ, New designs of adhesive joints for thick composite laminates. Composite Science and Technology 2001, 61, 19-40.

7. Grassi M, Cox B, Zhang X, Simulation of pin-reinforced single-lap composite joints. Composite Science and Technology 2006, 66, 1623-1638.

8. Aktas A, Dirikolu MH, An experimental and numerical investigation of strength characteristics of carbon-epoxy pinned-joint plates. Composite Science and Technology 2004, 64, 1605-1611.

9. Megueni A, Tounsi A, Adda Bedia E, Evolution of the stress intensity factor for patched crack with bonded hygrothermal aged composite repair. Materials and Design 2007, 28, 287-293.

10. Choi JH, Chun YJ, Failure load prediction of mechanically fastened composite joints. Journal of Composite Materials 2003, 37, 2163-2177.

11. Altan G, Topcu M, Experimental and numerical assessment of the improvement of the loadcarrying capacities of butterfly-shaped coupling 
components in composite structures. Journal of Mechanical Science and Technology 2010, 6, 1245-1254.

12. Kumar VRL, Bhat MR, Murthy CRL, Experimental analysis of composite single-lap joints using digital image correlation and comparison with theoretical models. Journal of Reinforced Plastics and Composites 2013, 32, 1858-1876.

13. Kim TH, Kweon JH, Choi JH, An experimental study on the effect of overlap length on the failure of composite-to-aluminum single-lap bonded joints. Journal of Reinforced Plastics and Composites 2008, 27, 1071-1081.

14. Seo DW, Lim JK, Tensile, bending and shear strength distributions of adhesive-bonded butt joint specimens. Composites Science and Technology 2005, 65, 1421-1427.

15. Nader JW, Dagher HJ, Lopez-Anido R, Size effects on the bending strength of fiber-reinforced polymer matrix composites. Journal of Reinforced Plastics and Composites 2011, 30, 309-316.

16. Dawood M, Taylor E, Rizkala S, Two-way bending behavior of 3-D GFRP sandwich panels with through-thickness fiber insertions. Composite Structures 2010, 92, 950-963.

17. Khalili SMR, Shokuhfar A, Hoseini SD, Bidkhori M, Khalili S, Mittal RK, Experimental study of the influence of adhesive reinforcement in lap joints for composite structures subjected to mechanical loads. International Journal of Adhesion \& Adhesives 2008, 28, 436- 444.

18. Ding K, Dhanasekar M, Flexural behaviour of bonded-bolted butt joints due to bolt looseness. Advances in Engineering Software 2007, 38, 598-606.

19. Abad J, Franco JM, Celorrio R, Lezaun L, Design of experiments and energy dissipation analysis for a contact mechanics 3D model of frictional bolted lap joints. Advances in Engineering Software 2012, 45, 42-53.

20. Aydin H, Temiz S, Experimental and Numerical Strength Analysis of Double Lap Joints Subjected to Tensile Loads. Materials Testing 2014, 56/2, 160-168.

21. Jones RM, Mechanics of Composite Material. Philadelphia: Taylor\& Francis, 1999.

22. Gibson RF, Principles of Composite Material Mechanics. McGraw-Hill Company, Singapore, 1994. 